\title{
Strengthening Teacher's Learning Management for Self-Reliance of Students in Thai Secondary School
}

\author{
Chalad Paso ${ }^{1}$, Chalard Chantarasombat ${ }^{1} \&$ Watanachai Tirasiravech ${ }^{1}$ \\ ${ }^{1}$ Faculty of Education, Mahasarakham University, Thailand \\ Correspondence: Chalad Paso, Faculty of Education, Mahasarakham University, Thailand. Tel: 668-7955-0098. \\ E-mail: Chalad1139@gmail.com
}

Received: September 28, 2016

Accepted: October 30, $2016 \quad$ Online Published: February 27, 2017

doi:10.5539/ies.v10n3p165

URL: https://doi.org/10.5539/ies.v10n3p165

\begin{abstract}
This research aimed to 1) study the present conditions, problems, and needs of teachers development in learning management in self-reliance for students in secondary schools, 2) develop a model for teacher development in learning management in self-reliance for students in secondary schools, and 3) evaluate the results of usage from teachers in learning management in self-reliance for students in secondary schools. Research methodology was based on research and development (R\&D) approach by the application of Participatory Action Research (PAR). There were seven processes ans stages involved as follows 1) study of the best practice, 2) participatory workshops to create awareness of the participants, 3) solutions and resources to improve teaching and learning of teachers, 4) creating alternative solutions and develop curriculum, 5) developing of analytical thinking skills and synthesis of curriculum in leaning management, 6) linking and transfer of knowledge, skills, attitudes of learning into practices, and 7) evaluation and reflection on the performance of teachers in learning to self-reliance of the student. The results showed that the model for teachers in learning management for self-reliance of students in secondary schools consisted of two main elements as follows 1) the process of participatory learning activities in seven steps, 2) the operation of participatory activities in fourteen sub-activities. The evaluation shown that the level of possibility, appropriateness, and usefulness were in the highest level.
\end{abstract}

Keywords: learning management, self-reliance, medium-size secondary school

\section{Introduction}

\subsection{Rationale}

Teacher development is important to improve the quality of students' learning. Nowadays, students under the globalization of the 21 st century need to be strengthened with the development skills to enhance the quality of their productivity for the competitive potential. Teachers have critical roles in the development of a complete human which are included: body, mind, intellect, knowledge, moral, ethics, and living culture. Therefore, they can collaboratively live happily with others in the world. Moreover, the quality of teachers is the key factor that affects the students' learning ability. Once the students obtain the opportunity to study with a skillful teacher, they will be able to develop for advance than studying with non-skillful teachers for three times (Office of the Education Council, 2012). In addition, international education perspective is gearing toward skillful teachers for learning experience management (Darling-Hammond, 2008; Gordon et al., 2009; Brookfield, 2015).

The strength of Thailand development has been nurtured by His Majesty King Bhumibol Adulyadej. His "Sufficiency Economy" is the foundation of the nation's competency and social development. Over three decades, the philosophy of sufficiency economic has been enbraced by different sectors as the appropriate conducts of life. The following is an excerpt from His royal speech in 1974:

"Economic development must be done step by step. It should begin with the strengthening of our economic foundation, by assuring that the majority of our population has enough to live on.... Once reasonable progress has been achieved, we should then embark on the next steps, by pursuing more advanced levels of economic development. Here, if one focuses only on rapid economic expansion without making sure that such plan is appropriate for our people and the condition of our country, it will inevitably result in various imbalances and eventually end up as failure or crisis as found in other countries." (Royal Speech, 1974, p. 12)

The concept of Sufficiency Economy had an influential role over economic crisis in 1997. It led the ways to 
recover the nation in resilient, balanced and sustainable development. In order to reiterate the concept for development, the National Economic and Social Development Board (NESDB) then conducted the expansion of the concept as following definition:

"Sufficiency Economy" is a philosophy that stresses the middle path as an overriding principle for appropriate conduct by the populace at all levels. This applies to conduct starting from the level of the families, communities, as well as the level of nation in development and administration so as to modernize in line with the forces of globalization. "Sufficiency" means moderation, reasonableness, and the need of self-immunity mechanism for sufficient protection from impact arising from internal and external changes.To achieve this, an application of knowledge with due consideration and prudence is essential. In particular great care is needed in the utilization of theories and methodologies for planning and implementation in every step. At the same time, it is essential to strengthen the moral fibre of the nation, so that everyone, particularly public officials, academic, businessmen at all levels, adheres first and foremost to the principle of honesty and integrity. In addition, a way of life based on patience, perseverance, diligence, wisdom and prudence is indispensable to create balance and be able to cope appropriately with critical challenges arising from extensive and rapid socioeconomic, environmental, and cultural changes in the world." (Piboolsravat, 2003)

From application of Sufficient Economy, the core of educational development is to create the students to meet educational standards and in line with the needs of society because they will be major forces in developing countries in the future. This goal is corresponded with the Revised National Educational Plan Year 2009-2016, Education Reform under the provisions of the National Education Act Year 1999, and the Amendment Act Year 2002. The aim of national education is to develop Thai citizen as a completed human with the full capability and being good in order to live with others in society happily. Implementation as of education reform to accomplish goals needs powerful and effective manner. It has to adhere the conditions and principles of reform stated by the Ministry of Education. The following principles are included: 1) School-based decision making. Schools perform decision based on independence and benefits to the learners, 2) Collaboration. It aims at various parties involved in education or stakeholders to contribute a joint educational management. The committee should comments or share supervision to school administration, 3) Decentralization. It aims at allocating management of the academic budget and general management by responsibility of Commission of Education Service Area Office and schools. 4) Accountability. It aims at defining the responsibilities and tasks of primary obligation. Whoever assigned any responsibilities, they need to monitor the success of outputs to secure the quality of education. (Office of the Basic Education, 2010: 45). School-based management and school effectiveness are main interests among school reform in other countries such as in US and Europe. (Aho \& Sahlberg, 2006; Dimmock, 2013)

\subsection{Research Problems}

From concept and experience in management of participatory education quality development among the medium-sized secondary schools under the Office of Secondary Education Service Area 27, there are conditions and context in participatory management for development of teachers which is not as efficient. These problems such as knowledge management, learning strategies, and problem solving methods are necessary for improving and developing schools management. Research and development of teachers in managing learning of students in medium-sized secondary schools based on self-reliance principle would be feasible for participatory development. If the model and innovation are discovered, it will be possible in solving problems of those schools.

The researcher who has the duty in the school as deputy director of academic affairs which responsible for organizing, promoting of teaching and learning management to serve education to school-aged population to receive a basic education extensively and with quality. So, it is research interest to study the phenomena and processes in the development of teachers in learning to self-reliance of students in midsize secondary schools. The intended research interest also evaluates the development of model to guide the learning management. It would produce the support for educational quality in consistent with standards, needs and satisfaction of those involved, and educational services in the future.

Purposes of the study are as follows:

1) To study the present problems of teachers in learning on self-reliance of students in secondary schools.

2) To study the effects of the development model in learning on self-reliance of students in secondary schools.

3) To study the satisfaction of the development model in learning on self-reliance of students in secondary schools. 


\section{Method}

The study was divided into three phases:

Phase 1: Study the present problems and needs in professional development for teachers in learning to self-reliance of students in secondary school. This included education theory, research, and related documents. Also conducting of in-depth interviews on current conditions, problems, and needs in professional development for teachers in learning to self-reliance of students.

Phase 2: Development of teachers in learning to self-reliance of students in secondary schools. The first step was to study resources of best practice and preparation the plan of participatory to develop teaching learning management. This involved planning within internal research team in order to prepare a development plan for teachers in learning to self-reliance of the students. The first development tool was achievement tests in knowledge management. Its discrimination power was between.217 and.689 with level of confidence.603. Second tool was knowledge test of self-reliance learning management. Its discrimination power was between.201 and.845 with the confidence level of. 742 .

Conceptual Model was the combination of concepts which were included Khemmani's (2010) authentic learning concept, Chantasonbat's (2008) theory of learning from practice, Ramasut's (1997) constructivism concept and participatory action research, Wongwanich's (2009) desirable characteristics of learners, and the survey results at schools where they were excel in teachers development. All conceptual elements were blended to be a model for teachers' development in learning self-reliance of students in mid-size schools. Then seven experts verified the model for its suitability, possibility, consistency, and benefit in practice. The result of verification was in the highest average $(\bar{X}=4.73)$. After then, the amendment was done by proposal of the experts. The final model was illustrated in Figure 1.

\section{Self-reliance Model: The Participatory Operational Research}

Step 1: Best Practice. Study visit of learning resources where best practice is performed, especially on how to develop teacher in excellent learning management. Self-sufficiency learning resource with local scholars is also included.

Step 2: Planning. Participatory planning activities. It included two activities which were the first activity on the meeting in understanding with participants and the second activity on the meeting in establishing awareness and initiative.

Step 3: Searching. Seeking of guidelines and resources. The third activity was creation of motivation among research team members. The fourth activity was to determine the focus of the development team.

Step 4: Creating. Intervention of problems. The fifth activity was related with providing of instruction manual in teacher development. The sixth activity was related to monitoring and updating the model.

Step 5: Problem Solving. Performing intervention to solve the problems. The seventh activity was to organize workshop for the teachers to have the ability to analyze and synthetic self-reliance curriculum. The eighth activity was preparation of lesson plans for self-reliance activities. The ninth activity was to implement learning activities of self-reliance lessons. The tenth activity was to draft the indicators of success. The eleventh activity was to collecting data on baseline learning outcomes.

Step 6: Knowledge Linkage and Transfer. Linking and transferring knowledge. The twelfth activity was evaluation the success of the operation while the thirteenth activity was on concluding the work performance. Final activity was the fourteenth one on knowledge sharing and expansion. 


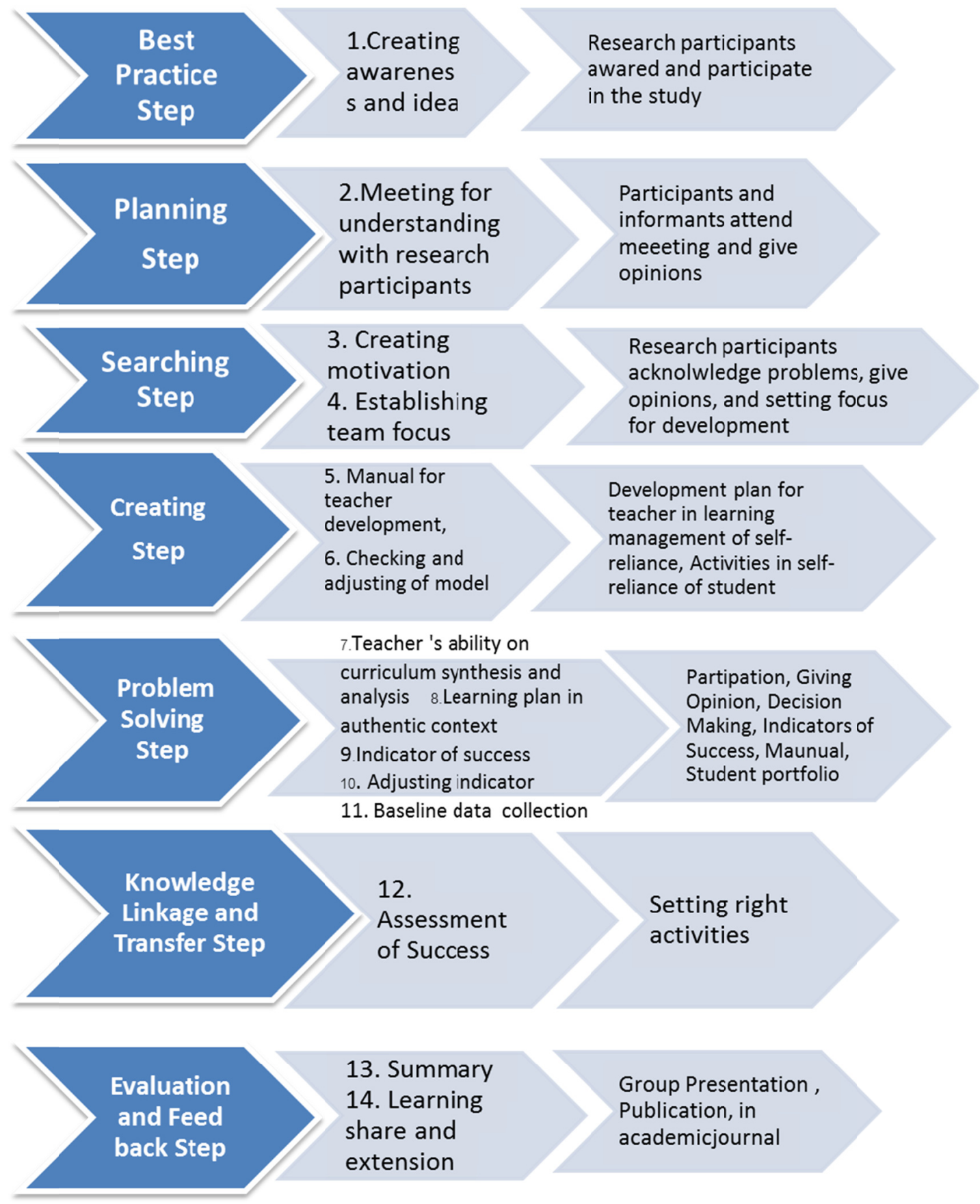

Figure 1. Model for teachers' development in self-reliance learning of students

\section{Data Collection}

\subsection{Model Development}

In this phase, the researcher and colleagues in school conducted a workshop in creative participation to engage the team in brainstorming and to discuss the indicators of success in the operation. Later, the researcher presented proposed model to the advisor and seven experts to validate the consistency between activities and indicators of success. This result yielded an average level $(\bar{X}=4.11)$. Suggestions were taken from the experts to make adjustment. Finally the model was contributed to the development of teachers in the curriculum for teaching students on self-reliance in school. Tools used to collect the data were semi-structured interviews, unstructured interview, participatory observation, and observation without participation, Before Action Report (BAR), Within Action Review (WAR), and After Action Report (AAR). Results from the experts were in an 
average level. Two key components were the participatory operational research which involved seven steps, and the development of teachers in learning to self-reliance for students in secondary schools which involved 14 sub-activities.

\subsection{The Participatory Operational Research}

The operation from the teachers' development model in learning for self-reliance of students in secondary schools, it found that the model was appropriate to the context. Research participants can perform activities in authentic learning environment. The model in learning management for self-reliance of students consists of: 1) Actual situation and the real problem in a specific context, 2) Critical thinking, problem solving, knowledge acquisition, and methodology, 3) Decision making by standards of real life, 4) Measurement and evaluation in all aspects. The model was used through the application of participatory research involving seven steps as follows.

The study visit to learning sites on how the best practices is developed. The focuses are on teacher development, curriculum management, and learning resources for self-sufficiency of local scholars.

Participatory planning workshop to engage participants in construction of a problem tree in order to brainstorm ideas. This workshop made knowledge management to be shared between teachers, students and parents for better understanding in the roles of stakeholders. It can develop and guide teachers in teaching students of self-reliance concept. Workshop participation was based on analysis of the past, present and future scenarios then prioritize the significance of the teachers' development process for self-reliance. Participants joining in the research would know their roles by analyzing the current state, demand, and development model. This was regarded as 'knowledge identification'. They could apply knowledge management to suite the style of learning. Learning collaboratively from practice could be used to do activity together as well as be used on a daily basis to resolve any issues.

Next process was team building which regarded to a meeting with the management, teachers, students and parents. There were 32 people who interested in joining the research team. It was to raise awareness and initiatives by providing understanding of the participatory work and roles in the performance of joint projects. School-level development staff was informed at by the researchers on how to operate the project and the importance of the involving activities. In participation, everyone must share ideas, join decision-making practice, join responsibility of beneficiaries, and join in concluding the program. The participatory action was also so included skills development and knowledge management in learning. The researcher asked for knowledge contribution from teachers by asking them to tell stories of desirable characteristics of successful learners. This made them to encounter each other in order to exchange knowledge with the research team. Then to summary the narratives and synthesize with the learning of self-reliance among students. The factor that should be improved as soon as possible is the role and duty of parents with involvement of learning to raise the quality of school education. It should be focusing on activities with the active participation of all sectors in learning. The stories had the consequences toward ideas to improve the quality of learning. Creation of those factors brought the incentive to participate, awareness of teamwork, and networking among team investigator. The effects occurred during trial practice; however the results from the operation could be confirmed again by the results.

Finding the model and resources. Activities were involved with an activity workshop to study the needs as well as building motivating for a researchers' team. They developed a curriculum for teachers to foster student in secondary school by applying the concept of learning reform. The reforms are included learning content, learning process, learning outcomes, and learning management. These aimed to create a focus for the development team. The strategies include collaborative teamwork strategy, creation of a shared focus and common vision, school-base constructivism to build knowledge by using school. The strategies targeted at professional development for teachers in the curriculum.

The promotion and development of desirable features. Its focus was on the development of the curriculum for teachers to foster student participation of outstanding community. The participants were urged to be motivated to work together and see the positive impact of learning. They worked together to succeed by learning alongside practical problems in the implementation and joint research question. Then the features were synthesized by various elements. Every group found the systematic planning. They worked with the participation of all parties involved. Evaluate of results was conduct to improve the results the performance of students, teachers and parents. The assessment results are used again to plan and develop further operation. In summary, it is a practical work of PDCA cycle: P (Plan), D: (Do or Practice), C (Check), and A (Act).

Creating a troubleshooting guide. Researchers and colleagues made a teachers' manual for improvement and monitoring. Workshops were used as technique to engage constructive operation within a team every week. They 
shared learning and knowledge creation that had occurred. Also during the event, if the problem could be adjusted as appropriate, this provided flexibility to the teaching activities of the group. The adjustment was not be additional workload to teachers' duty while participated in this research. Once they had understanding and co-investigation on the research framework for knowledge exchange, their comments and needs to effective work reflected the idea of co-operation in research to create a shared vision. Learning management to foster students self-reliance involved five stages. 1) Analyze and synthesis of school curriculum, 2) Preparation course for self-reliance students, 3) Preparation of learning units, 4) Preparation of lesson plans, and 5) Authentic learning management. This made all the teachers who attended the workshop to involve with a participatory learning. They could see the importance of the process design. Teacher can be a manager to self-reliance learning. Participants would be able to transfer knowledge to other students and teachers on how to plan a project that led to the idea of the joint research. They could adopt the project planning by the group of 14 features.

The operating of problem solving. The researcher and co-researchers had set the common target for operation. There were definite activities and operations which included: teachers development for the ability to analyze, synthesize the course curriculum, self-preparation of lesson plans for self-reliance. Data was collected from baseline data and authentic learning. The collection was included three stages: before proceeding, during operation, and after the completion. Participants worked to define the indicators of success by studying the operational behaviors in line with the activity of 14 events. There were 70 indicators of success occurred from the implementation of all activities. Manual of operation was the output of those tasks which result from the preparation of operation. It focused on developing students to be self-reliant in the field of education, social, and economic aspects.

Linking the research and knowledge transfer. Research participants had jointed activities in linking and transferring the knowledge, skills, and attitude. Learning was aimed at authentic self-reliance circumstance to students. Operational plan was developed to practice and agreements were developed to achieve a target operation. The researcher and co-researcher had brought teacher leaders, student leaders, and parents leaders together to make understanding for the development and management knowledge in authentic learning to enhance self-reliance of students. All aspects were related to education, social, and economic sides. Before the development, they had the lessons of practicality on learning management to bring awareness to the researchers and participants. Then the group provides information on common assessments and gave summary of self-reliance learning among students. Therefore, they had common development of the implementation plan and improve it from the results on practical feature of students' self-reliance.

Summary of knowledge linkage to self-reliance was as follows:

Self-reliance on education of students was observed by focusing on the features that important to students. It worked by allowing students to apply their knowledge and skills to their fullest capability before asking for help from others. When they encounter academic problem, they used efforts to solve the problem based on accuracy and honestly; not copying the works of others and not submitting those works to instructor for the points. They had to learn by themselves to achieve self-knowledge and community contribution. Self-reliance was not a burden, but as an activity that was practiced daily by the students together with teachers, students and parents to design the co-operation plan among each other.

Self-reliance of the students on social features, it found that they have tried to use their ability at fully capacity to integrate with others in creating problem solving. They were not being burdens to the group's work. They tried to go smoothly and were willing to help each other with no excuse. They tend to think of the advantage the members before the making operation. They concerned with developing their own features and personal activities to perform as in a group. This could eliminate selfishness by overseeing self-centered decision-making. In the experimental group, they did learning together and they shared the steps in making possibility to develop the characteristics of the students for group contribution toward the development for the group level.

Self-reliance on economic, the characteristics of students tended to be trying to use their fully financial skills; as to lower expenses, to add income for personal expenses, and to ease parents' burden. Their self-reliance could be without affecting education such as the production of consumer goods with cost effectiveness, purchasing food in appropriate amount, planning of spending, and keeping records in savings accounts. These practices had been prepared them to develop their personal features and communal features development.

Evaluation and reflection. Researchers and co-researchers organized a number of seminars for knowledge and learning exchange during the implementation of the roadmap plan. The activities outlined in the roadmap were used to revise the plan. They had to be joint analysis and synthesis to validate every activity. There was an evaluation process by using a form of performance record during operation (WAR). The collaborative research 
brought together the assessment results to analyze the flaws to improve the indicators of success. Then, the summary of the monthly meeting led to the development and evaluation of cooperation, changes, success and results of operations. An adjustment of quantitative assessment was based on the satisfaction of learning management for self-reliance. Indicators of learning achievement were determined by teachers. The conclusion of the learning management was drawn from various platforms to empower assessment in summarizing the knowledge of new findings or conclusions learned from the experience. It was to provide professional development for teachers in learning to self-reliance of students in secondary schools as the purposes of research.

The follow-up operation of the teachers in this collaborative research was conducted to evaluate the performance, assessment, and techniques by using triangulation based assessment to measure the success and to monitor evaluation of the school's co-research team and administrators. People involved were teachers, parents, and students. They all had joint in the assessment after conducting the research. The assessment stages were as follows: 1) assess the behavior to compare between pre-operation and post-operation, 2) assess satisfaction in operation after operation the implementation. Researchers had collected the data results of performance thoroughly. The data collected is analyzed individually and interpret data which gathered from questionnaires, interviews, observation, recording, and practice. The assessment aimed to analyze the purpose of the study. The data obtained from the reflection was later transferred to be described by descriptive analysis. The results were used to improve learning activities in the future operation and activities. Teachers used the results in learning management on the students in secondary schools in operations of integrated joint decision, joint responsibility, co-beneficiaries, and collaborative participation.

\section{Results}

The operating results were also found:

1) Co-researchers were included school's management, leading teachers, leading students, and leading parents. All leaders from three groups had organized knowledge management session based on the origin of knowledge, knowledge inquisition, questioning and solution. Finally they obtained the knowledge needed for the success of the group.

2) Co-researchers had gained learning process which derived from authentic learning environment. They had knowledge exchange and application of knowledge.

3) Co-researchers had taken the knowledge from themselves to combine with the new knowledge that had been added. The new knowledge was suitable and met the needs of students, schools and communities. In order to analyze and synthesize, they did the followings: 1) Curriculum analysis, 2) Preparation course to foster student learning units, 3) Preparation of learning units, 4) Planning of learning unit, and 5). Implementing the learning units with authentic set of knowledge and the work of the co-researchers.

The results of operations development for teachers in learning management to self-reliance in secondary schools, it found that teachers planned learning experience for pupils to develop self-reliance from practical implementation. The creation of good behavior, both to themselves and to the public, was a desirable feature. Self-reliance had found in the field of education, social, and economic. Self-reliance was a metric to measure the success in the implementation of activities and assessing of student behavior. In summary, students' behaviors in terms of their personal features, public features, and learning characteristics were all in the most level.

Assessment of the satisfaction contributing to the development of teachers in learning to self-reliance of students in secondary schools was overall in the most level. The participants, consisting of administrators, teachers, students, parents were at the highest level. As a result, the quality of the learner was as follows:

1) Personal level. Students had developed in life skills, team working, knowledge enthusiastic, and continuous learning. They can be self-reliance in an education, social and economic aspect.

2) Public level. Teachers had developed with effectiveness of teaching. Student learning experience was emphasized with encouragement to develop toward educational standards. Such developments were maintained with excellence in line with the education reform.

3) Organizational level. School obtained quality assurance system and it had professional development plan in learning management to self-reliance of the students. 
Table 1. Satisfaction toward the development of the curriculum for teachers to foster self-reliance of students in the medium secondary school

\begin{tabular}{|c|c|c|c|}
\hline Items & $\bar{X}$ & SD. & Level of \\
\hline \multicolumn{4}{|c|}{$\begin{array}{l}\text { Elements of teachers development in learning management to self-reliance of } \\
\text { students in secondary schools }\end{array}$} \\
\hline 1. The study visit on learning sources of the best practice & 4.51 & 0.42 & Highest \\
\hline 2. Participatory workshop & 4.52 & 0.59 & Highest \\
\hline 3. Guidelines and resources formulation & 4.65 & 0.49 & Highest \\
\hline 4. Creating of solutions & 4.43 & 0.66 & High \\
\hline 5. Practice of solutions & 4.65 & 0.49 & Highest \\
\hline 6. Linkage and transferring of knowledge, skills, attitudes & 4.54 & 0.34 & Highest \\
\hline 7. Evaluation and reflection & 4.57 & 0.36 & Highest \\
\hline \multicolumn{4}{|l|}{ Elements of learning and curriculum management of teachers } \\
\hline 8. Analysis of the core curriculum & 4.52 & 0.59 & Highest \\
\hline 9. Synthesis of school curriculum & 4.52 & 0.59 & Highest \\
\hline 10. Course design of department & 4.65 & 0.49 & Highest \\
\hline 11. Preparation of course description & 4.53 & 0.66 & High \\
\hline 12. Preparation of learning unit & 4.65 & 0.49 & Highest \\
\hline 13. Preparation of lesson plans & 4.54 & 0.34 & Highest \\
\hline \multicolumn{4}{|l|}{ Authentic learning activities and instruction } \\
\hline 14. Define of the problems from real context & 4.43 & 0.66 & High \\
\hline 15. Analysis of problem/knowledge and information acquisition & 4.65 & 0.49 & Highest \\
\hline 16. Collective decision on problem solving & 4.65 & 0.49 & Highest \\
\hline 17. Decision based on the real-life benchmark & 4.52 & 0.67 & Highest \\
\hline 18. Exchange of knowledge and insights that reflects actual learning & 4.57 & 0.36 & Highest \\
\hline 19. Measuring and evaluating the knowledge, skills, and attitudes & 4.65 & 0.49 & Highest \\
\hline \multicolumn{4}{|l|}{ Features of self-reliance in students } \\
\hline 20. Learning by practice & 4.15 & 0.80 & High \\
\hline 21. Self-reliance in education & 4.35 & 0.85 & High \\
\hline 22. Self-reliance in society & 4.45 & 0.78 & High \\
\hline 23. Self-reliance in economic & 4.39 & 0.72 & High \\
\hline Overall Level & 4.53 & 0.56 & Highest \\
\hline
\end{tabular}

Table 2. Satisfaction of the development model of teachers in learning management in self-reliance of students in secondary schools

\begin{tabular}{|c|c|c|c|}
\hline Items & $\bar{X}$ & SD. & Level of Satisfaction \\
\hline \multicolumn{4}{|l|}{ Personal level } \\
\hline 1. Awareness in the importance of cooperative learning & 4.52 & 0.59 & Highest \\
\hline 2. Enthusiastic Learning and ready for life-long learning & 4.65 & 0.49 & Highest \\
\hline 3. Systematic thinking. initiatives & 4.43 & 0.66 & High \\
\hline 4. Responsibility for continued learning & 4.65 & 0.49 & Highest \\
\hline 5. Works or portfolio as media in knowledge exchange & 4.54 & 0.34 & Highest \\
\hline 6. Taking note of the performance after its operation as ongoing basis & 4.45 & 0.85 & High \\
\hline 7. Use of Technology and Innovation in practice & 4.39 & 0.72 & High \\
\hline 8. Use of manual as guideline to develop education and operation effectively & 4.52 & 0.67 & Highest \\
\hline 9. Learning new things & 4.57 & 0.36 & Highest \\
\hline $\begin{array}{l}\text { 10. Obtaining experience from the involvement of stakeholders from learning } \\
\text { practices }\end{array}$ & 4.65 & 0.49 & Highest \\
\hline Overall Level & 4.54 & 0.57 & Highest \\
\hline \multicolumn{4}{|l|}{ Public Level } \\
\hline 1. Create a vision and goal by brainstorming from participants & 4.10 & 0.59 & High \\
\hline 2. Team building by training, workshops, and study & 4.43 & 0.66 & High \\
\hline 3. Participatory planning leads to action. & 4.43 & 0.66 & High \\
\hline 4. Encouraging group activities and teamwork & 4.65 & 0.49 & Highest \\
\hline
\end{tabular}




\begin{tabular}{llll}
\hline 5. Operation as planning and to improve performance & 4.65 & 0.49 & Highest \\
6. Responsible for the work assignment & 4.52 & 0.67 & Highest \\
7. Creating new knowledge and exchange among community members & 4.57 & 0.36 & Highest \\
8. Discussions for ongoing performance & 4.65 & 0.49 & Highest \\
9. Learning to work as a team & 4.65 & 0.49 & Highest \\
10. Obtaining experience from the involvement of the team & 4.52 & 0.67 & Highest \\
Overall Level & 4.52 & 0.56 & Highest \\
Organization Level & & & \\
1. Atmosphere that promotes learning and participation. & 4.52 & 0.59 & Highest \\
2. Creating of corporate culture of learning & 4.65 & 0.49 & Highest \\
3. Development of people in the organization for full potential & 4.43 & 0.66 & High \\
4. Information system for continuous improvement. & 4.65 & 0.49 & Highest \\
5. Indicators of organizational success as the goals of development. & 4.54 & 0.34 & Highest \\
6. Tracking System and audit of operation & 4.45 & 0.72 & High \\
7. Knowledge set as research of innovative learning of participants & 4.35 & 0.59 & High \\
8. School to organize knowledge on interested issues and knowledge storing & 4.43 & 0.66 & High \\
9. The school has its own identity of cooperative & 4.45 & 0.85 & High \\
10. School is learning organization & 4.47 & 0.85 & High \\
Overall Level & 4.49 & 0.62 & High \\
Overall Level & 4.52 & 0.58 & Highest \\
\hline
\end{tabular}

\section{Discussions}

From the results of the development model of teachers in learning to self-reliance of students in secondary schools, the overall level was in medium. Professional development for teachers in learning to self-reliance of students in secondary schools comprises of five processes of action research and six steps of operation as defined in 14 activities. The result of the model was successful as expected, due to the development model which the researchers used based on the concept of analysis and synthesis, as well as experts' opinion in terms of knowledge management and the development of techniques. The result was also corresponded with Panich (2005), and Chantarasombat (2007, 2008, 2009, 2010), which the AAR (After Action Response) was used to share the knowledge and being evidence to indicate success. AAR has been widely used for various organization for profit experiences (Darling et al., 2005) and performance assessment (Villado \& Arther, 2013).

Participation learned from knowledge management contributes to self-reliance of students in secondary schools. Participants became active learners in different roles such as CKO (Chief Knowledge Officer), KF (Knowledge Facilitator), KP (Knowledge Practitioner), NT (Note Taker) and NM (Network Manager). Knowledge management is an effective tool to manage roles and responsibilities among members of an organization (Despres \& Chauvel, 2012; Homsin, Chantarasombat, \& Yeamsang, 2015; Perry, 2016).

Learning practices, coupled with the knowledge of the issue led to questioning for solution with practicality. This brought the knowledge leading to issues which were included: identifying knowledge, knowledge creation, and knowledge management. The system was interchangeable and applicable to existing knowledge. This finding was in line with Wasi (2002). He noted that learning of one person is not enough to make it successful because the people, organizations, and institutions are not only involved with sole learning, but rather learning together in practice for successful management of knowledge through a practicality. Also Plynoi (2003) asserted that AAR is an important learning tool to extract the essence of knowledge. It reserves the findings of the person or organization appropriately. Moreover, AAR is a significant tool to improve the performance and development of work. It reflects response after the work operation immediately. This is one way to make learning and development of people and project (Darling et al., 2005). Knowledge management needs to cooperate among all related factors and tools (Rasula, Vuksic, \& Stemberger, 2012; Hislop, 2013).

The result of the satisfaction of contributing to the development of teachers in learning to self-reliance of students in secondary schools, it found that their overall level was in highest level. This result helped in achieving development of activities and joint ideas among co-beneficiaries. Similarly, decision making could be made and finalized from administrators, teachers, parents, and students. Teachers who were the result in the development of the curriculum could foster student success in school due to cooperative planning system. Teachers were carefully prepared in working through this participation. The results were used to evaluate the performance periodically. In addition to the result, Ramasutra (1997) had noted that participatory operation 
involved 9 of following steps: 1) Community preparation, 2) Training co-researchers, 3) Setting research scheme, 4) Collecting data, 5) Processing and analyzing data, 6) Discussing finding with community, 7) Planning on community, 8) Implementing plan, and 9) Following-up and evaluation. Moreover, Chantarasombut (2009) suggested similarly as followings: 1) Community preparation, 2) Building motivation, awareness, cooperation, and vison, 3) Planning of team potential, 4) Implementing the plan and development, and 5) Summative evaluation. Homsin (2014) noted how to carry out the participatory research which involved seven steps as followings: 1) Problems and needs, 2) Motivation and awareness 3) Planning and innovation development, 4) Creating measures of success, 5) Implementation of the plan, 6) Evaluation, and 7) Exchange of learning.

\section{Recommendation}

\subsection{Recommendations for Model Implementation}

Model is to be used effectively with the manual as a guide for development of teachers and curriculum to foster students' self-reliance. Operation with this means is important to guide the development of students' abilities. They would be able to be reliance in the society and economic for creating consciousness in a good way.

In order to adopt the model to improve the quality of learning outcome in secondary schools, it is necessary to follow 6 steps and procedures necessary and fully understand each activity. Application has to apply in accordance with the specific context of school and community and its current conditions and needs.

Teachers should lead learning activities in accordance to the lifestyle of students to develop their full ability. Teachers should be their role models for the implementation of good deed both in personal and collective benefit since teachers are influential to the students.

Conducting a manual for the best practices needs to adhere to the terms of the stakeholders' involvement because the development of teachers in learning to self-reliance of students in secondary schools has to be treated continuously and seriously for being tangible and sustainable.

\subsection{Recommendations for Further Research}

Researcher should develop a model for teachers in learning to self-reliance of students in secondary schools to other kinds of organization or community with similar contexts. This could cause variety of learning and strong networking.

Researcher should study and develop the role and functions of the school's board commission on the development of basic education teachers and curriculum for medium secondary school students in the self-reliance.

Researcher should study and develop learning conditions in developing competencies to the basic education leaders, community leaders, and corporate groups to be effective in the management of education. They could improve the quality of students in medium secondary schools. These people could therefore effectively manage the learning process as the facilitators in the community.

\section{References}

Aho, E., Pitkanen, K., \& Sahlberg, P. (2006). Policy Development and Reform Principles of Basic and Secondary Education in Finland Since 1968. Education Working Paper Series. Number 2. Human Development Network Education.

Brookfield, S. D. (2015). The skillful teacher: On technique, trust, and responsiveness in the classroom. John Wiley \& Sons.

Chantarasombat, C. (2007). Development of Knowledge Management Model for Community Organization (Master of Education Thesis, Mahasarakam: Mahasarakam University Press).

Chantarasombat, C. (2008). Participatory Action Research for Community Development (2nd ed.). Khon Kaen: Klangnanawittaya Printing.

Chantarasombat, C. (2009). Development a Knowledge Management Model for Self-Reliant Communities. Medwell Journals, 4(4), 392-6.

Chantarasombat, C. (2010). Knowledge Management and School Administration into Learning Organization. Mahasarakam: Faculty of Education, Mahasarakam University Press.

Darling, M., Parry, C., \& Moore, J. (2005). Learning in the thick of it. Harvard Business Review, 83(7), 84.

Darling-Hammond, L. (2008). Teacher learning that supports student learning. Teaching for intelligence, 2, 91-100. https://doi.org/10.4324/9780203880968.ch48 
Despres, C., \& Chauvel, D. (2012). Knowledge horizons. Routledge. https://doi.org/10.1016/B978-0-7506-72474.50002-1

Dimmock, C. (2013). School-based management and school effectiveness. Routledge. https://doi.org/10.4324/ 9781315824727

Gordon, J., Halász, G., Krawczyk, M., Leney, T., Michel, A., Pepper, D., \& Wiśniewski, J. (2009). Key competences in Europe: Opening doors for lifelong learners across the school curriculum and teacher education. CASE network Reports No. 87. https://doi.org/10.2139/ssrn.1517804

His Majesty King Bhumibol Adulyadej. (1974). Royal Speech, December 4, 1974. Bangkok: Amarin Printing and Publishing.

Hislop, D. (2013). Knowledge management in organizations: A critical introduction. Oxford University Press.

Homsin, N. (2014). Using Knowledge Management for Developing Secondary School Students' Public Mind in Thailand. International Journal of Education and Research, 2(10), 551-566.

Homsin, N., Chantarasombat, C., \& Yeamsang, T. (2015). The Result of Developing Secondary School Students' Public Conscience through Process-Knowledge Management in Thailand. International Education Studies, 8(7), 240. https://doi.org/10.5539/ies.v8n7p240

Ministry of Education. (2008). Core Curriculum for Basic Education Curriculum B.E. 2551. Bangkok: National Agricultural Cooperative Press.

Panich, W. (2005). Knowledge Management for Practitioners. Bangkok: Institute for Social Knowledge Management.

Perry, M. (2016). Does a Knowledge Management Community Manage Knowledge? Organizational Knowledge Facilitation through Communities of Practice in Emerging Markets, 165. https://doi.org/10.4018/978-1-5225-0013-1.ch009

Piboolsravut, P. (2003). Economic Theoretical Framework of the Sufficiency Economy Philosophy. Bangkok: Office of National Economic and Social Development Board (NESDB).

Plynoi, N. (2003). KM Lessons: Growing Rice in Sustainable Agriculture. Annual Report of Knowledge Management Thailand. Bangkok: Usa Printing.

Ramasutra, P. (1997). Participatory Operational Research. Bangkok: P.A. Livings Printing.

Rasula, J., Vuksic, V. B., \& Stemberger, M. I. (2012). The impact of knowledge management on organisational performance. Economic and Business Review for Central and South-Eastern Europe, 14(2), 147. https://doi.org/10.7206/mba.ce.2084-3356.159

Villado, A. J., \& Arthur Jr, W. (2013). The comparative effect of subjective and objective after-action reviews on team performance on a complex task. Journal of Applied Psychology, 98(3), 514. https://doi.org/10.1037/a0031510

Wasi, P. (2002). Knowledge Management. Journal of Continue Reforms, 5(5), 74-76.

\section{Copyrights}

Copyright for this article is retained by the author(s), with first publication rights granted to the journal.

This is an open-access article distributed under the terms and conditions of the Creative Commons Attribution license (http://creativecommons.org/licenses/by/4.0/). 